\title{
Experience of mGluR1 Gene Therapy in Transgenic Models of SCA1 Mice
}

\author{
DOI: $10.17691 / \mathrm{stm} 2016.8 .4 .19$ \\ Received March 28, 2016
}

A.N. Shuvaev, MD, PhD, PostDoc, Department of Neurophysiology';

Researcher, Research Institute of Molecular Medicine and Pathobiochemistry²; H. Hirai, MD, PhD, Professor, Department of Neurophysiology ${ }^{1}$

${ }^{1}$ Gunma University Graduate School of Medicine, 3-39-22 Showa-machi, Maebashi, Gunma, 371-8511, Japan; ${ }^{2}$ Krasnoyarsk State Medical University named after Professor V.F. Voino-Yasenetsky, 1 Partizana Zheleznyak St., Krasnoyarsk, 660022, Russian Federation

\begin{abstract}
Spinocerebellar ataxia type 1 (SCA1) is a progressive neurodegenerative disease that presents with cerebellar ataxia and motor learning defects. Previously, we examined a mouse model of SCA1 and found a progressive functional impairment of metabotropic glutamate receptor (mGluR) signaling including dendritic $\mathrm{Ca}^{2+}$ signals and a consequent loss of short- and long-term synaptic plasticity at parallel fiber-Purkinje cell synapses in the early disease stage (12 postnatal weeks) prior to Purkinje cell death. According to this findings we suspected that enhancement of mGluR signaling by virus expression of mGluR1 selectively in Purkinje cells should lead to an improvement of motor performance in SCA1 mice. For this aim we construct viruses in a head of adeno-associated virus and murine stem cell virus promoters expressing mGluR1 and green fluorescent protein. Unfortunately, overexpression of this gene constructs gives the opposite effect. Examination of this phenomena leads to understanding of mGluR1 dependent mechanisms of dendritic arborization, synaptogenesis and synaptic plasticity in Purkinje cells. Thus, we found that mGluR1 signaling is a critical but not unique molecular in SCA1 pathogenesis. Also this negative result shows the complicity and ambiguousness of virus therapy benefit.
\end{abstract}

Key words: spinocerebellar ataxia; SCA1; mGluR1; RORa.

Introduction. Spinocerebellar ataxia type 1 (SCA1) is an inherited neurodegenerative disease, caused by a mutant Ataxin-1 gene with an abnormally expanded polyglutamine tract. SCA1 exhibits cerebellar ataxia and motor learning defects in a progressive manner [1]. SCA1 pathogenesis is closely related to gene regulation by the transcription factor, retinoid-related orphan receptor a (ROR $\alpha$ ), which is abundantly expressed in cerebellar Purkinje cells (PCs). Normal Ataxin-1 forms a transcriptional complex with RORa via the transcriptional coactivator Tip60 and this complex transactivates ROR $\alpha$ target genes. The mutant Ataxin-1 prevents its interaction with RORa and enhances RORa degradation with unknown mechanisms, causing a subsequent decrease in RORa-mediated gene expression [2]. Reasonably, downregulated gene sets in SCA1 model mice overlap considerably with those in mice with classical RORadeficient mutation, 'staggerer' [2], which causes congenital ataxia and cerebellar hypoplasia [3].

Our previous study showed that metabotropic glutamate receptor type 1 (mGluR1)-mediated signaling at cerebellar parallel fiber (PF)-Purkinje cell (PC) synapses is completely disrupted in homozygous 'staggerer' mutant and partially disrupted in transgenic SCA1 mice $[4,5]$, which is essential for proper motor coordination and learning $[6,7]$. In the present study, we tried to rescue ataxic phenotype in young transgenic SCA1 model mice develop impairment of mGluR1-mediated responses at PF-PC synapses in a progressive manner before PC death [1]. For this aim we produced virus constructions in a head of adeno-associated virus (AAV) and murine stem cell virus (MSCV) promoters which were express mGluR1 and green fluorescent protein (GFP). Increasing of mGluR1 protein in PCs of transgenic SCA1 mice expressing L7-4mCMV-GFP-P2A-mtTA+TRE-HA-mGluR1 and MSCV-GFP-P2A-mGluR1-WPRE was shown by registration current through TRPC3 channels which are highly dependent on mGluR1 pathways [8].

Materials and Methods. All procedures for the care and treatment of animals were carried out according to the Japanese Act on the Welfare and Management of Animals and the Guidelines for the Proper Conduct of Animal Experiments issued by the Science Council of Japan. The experimental protocol was approved by Gunma University Animal Care and Experimentation Committee (07-015 and 04-44). All efforts were made to minimize suffering and to reduce the number of animals used in this study. In most experiments, we used transgenic SCA1 model mice (SCA1 transgenic; heterozygous B05 line carrying the human Ataxin-1 gene with an extended 82 glutamine tract under control of the PC-specific L7 promoter) and wildtype (WT) mice of both sexes of the FVB background [9].

For contacts: Anton N. Shuvaev, e-mail: shuvaevanton@hotmail.com 
SCA1 transgenic mice were kindly provided by Dr. Harry T. Orr at the University of Minnesota, Minneapolis, MN, USA.

Electrophysiology. Parasagittal cerebellar slices (200 $\mu \mathrm{m}$ in thickness) were prepared, and whole-cell recordings were conducted as described previously [10]. Briefly, mice were deeply anesthetized by inhalation of isoflurane $(3 \%)$ and killed by decapitation. The whole brain was quickly dissected out and immersed for several minutes in an ice-cold solution containing the following (in $\mathrm{mM}$ ): 234 sucrose, $26 \mathrm{NaHCO}_{3}, 2.5 \mathrm{KCl}, 1.25 \mathrm{NaH}_{2} \mathrm{PO}_{4}$, 11 glucose, $10 \mathrm{MgSO}_{4}$, and $0.5 \mathrm{CaCl}_{2} ; \mathrm{pH} 7.4$, when bubbled with $95 \% \quad \mathrm{O}_{2}$ and $5 \% \quad \mathrm{CO}_{2}$. Parasagittal slices of cerebellar vermis were obtained using a microslicer (ZERO1, Dosaka EM, Japan). The slices were maintained in an extracellular solution containing the following (in $\mathrm{mM}): 125 \mathrm{NaCl}, 2.5 \mathrm{KCl}, 2 \mathrm{CaCl}_{2}, 1 \mathrm{MgCl}_{2}, 1.25 \mathrm{NaH}_{2} \mathrm{PO}_{4}$, $26 \mathrm{NaHCO}_{3}, 10 \mathrm{D}$-glucose, and $0.05-0.10$ picrotoxin. This solution was bubbled continuously with a mixture of $95 \%$ $\mathrm{O}_{2}$ and $5 \% \mathrm{CO}_{2}$ at room temperature for at least $45 \mathrm{~min}$ before starting the recordings. Whole-cell recordings were made from $\mathrm{PCs}$ using intracellular solution containing the following (in mM): 140 Cs-gluconate, $8 \mathrm{KCl}, 10 \mathrm{HEPES}$, $1 \mathrm{MgCl}_{2}, 2 \mathrm{MgATP}, 0.4$ NaGTP, 0.2 EGTA (pH 7.3 adjusted with $\mathrm{CsOH}$ ). PCs were voltage-clamped at $-70 \mathrm{mV}$ to record PF-mediated excitatory postsynaptic currents (EPSCs) and at $-10 \mathrm{mV}$ to record climbing fiber (CF)-mediated EPSCs. The passive electrical properties of the PCs were estimated using averaged traces of $\sim 20$ current responses (acquisition; low-pass filtered at $10 \mathrm{kHz}$ and sampled at $50 \mathrm{kHz}$ ) and evoked by hyperpolarizing voltage pulses (from -70 to $-75 \mathrm{mV}, 500 \mathrm{~ms}$ duration). Liquid junction potentials were not corrected in this study. Analysis of electrophysiological and imaging data was performed using pClamp10 (Molecular Devices, USA), Andor iQ software (Andor Technology, UK), and Igor Pro with NeuroMatic software (WaveMetrics, USA).

Selective stimulation of CFs and PFs was confirmed by paired-pulse depression and paired-pulse facilitation of EPSC amplitudes (at a 50-ms interstimulus interval), respectively. For the recordings of mGluR1-mediated slow EPSCs, the strength of the electrical stimulation was adjusted to produce AMPA receptor-mediated fast EPSCs with an amplitude of $\sim 500 \mathrm{pA}$. We subsequently applied 2,3-dioxo-6-nitro-1,2,3,4-tetrahydrobenzo[f] quinoxaline-7-sulfonamide (NBQX, $20 \mu \mathrm{M})$, an AMPAtype glutamate receptor antagonist, and slow EPSCs were elicited by applying 10 or 25 electrical stimuli to PFs at $200 \mathrm{~Hz}$. To examine short-term synaptic depression (SSE - synaptically evoked suppression of excitation and DSE - depolarization-induced suppression of excitation), PF-EPSCs were recorded every $5 \mathrm{~s}$. After monitoring basal PF-EPSCs for $1 \mathrm{~min}$, we applied PF burst stimulation (a train of 50 stimuli at $100 \mathrm{~Hz}$ ) to induce SSE, and a single depolarizing pulse (5 s from -70 to $0 \mathrm{mV}$ ) to the recorded PC for DSE induction. Amplitudes of subsequent PF-EPSCs were normalized to the mean basal value of two basal responses evoked before the induction stimulation.
For analysis of long-term depression (LTD), PFEPSCs were monitored every $10 \mathrm{~s}$. To induce LTD, we applied conjunctive stimulation which consisted of 30 single PF stimuli paired with single $200 \mathrm{~ms}$ depolarizing pulses $(-70$ to $+20 \mathrm{mV})$ repeated at $1 \mathrm{~Hz}$. Averaged amplitudes of PF-EPSCs over 1 min were normalized to the baseline value, which was the average of the $1 \mathrm{~min}$ responses (six traces) that occurred just before the conjunctive stimulation.

Adenoviral and lentiviral vectors production and cerebellar injection. Normal mGluR1 and GFP genes were inserted into a pcDNA3.1 expression vector (Invitrogen, USA) and divided by P2A element. Next, they were transferred from pcDNA3. 1 into the pCL20c lentiviral vector plasmid, which expresses transgenes under control of the MSCV promoter. HIV-derived lentiviral vectors pseudotyped with vesicular stomatitis virus $G$ protein were used in this study [10]. The backbones of the helper plasmids were derived from pCAGGS [11]. The detailed procedure for viral vector production was described in our previous reports [10]. Viral titers were assessed by counting the number of GFP-expressing cells following the transduction of HEK 293T cells [10]. We used lentiviral vector expressing MSCV-GFP-P2A-mGluR1WPRE with the titer of $3.9 \pm 0.8 \cdot 10^{10}$ transduction units per $\mathrm{ml}$ ( 6 batches). The viral solutions were stored at $4^{\circ} \mathrm{C}$ and used within 1 week. Ten microliters of lentiviral vector solution were injected into the subarachnoid space over the cerebellar vermis of 1-week-old (P6-P7) anesthetized WT C57BL/6 mice. Seven days are reported to be long enough for efficient transduction after lentivirus injection $[10,12]$. Most of the transduced cells were limited to PCs under control of the MSCV promoter [12].

Production of AAV vectors. mGluR1 and GFP were specifically expressed in cerebellar PCs by PC-specific L7-4 mCMV promoter [13]. To express a therapeutic gene in PCs using adeno-associated viral vector serotype-9 (AAV9), we used L7-4 promoter, which possesses strong transcriptional activity in PCs [12]. The expression plasmids pAAV/L7-4mCMV-GFP-P2A-mtTA and pAAV/ TRE-HA-mGluR1 were obtained via enzymatic reactions using pNAV [14]. Initially, pAAV/L7-4 was generated by the insertion of the L7-4 promoter fragment with bluntedMlul and BamHI sites into blunted-Xhol and BamHI sites of pNAV. Subsequently, the GFP-P2A-mtTA cassette with blunted-Notl and BamHI sites was subcloned into pAAV/ L7-4 with blunted-EcoRI and BamHI sites.

Recombinant single-strand AAV9 vectors were generated by the cotransfection of HEK293 cells with three plasmids, pAAV/L7-4mCMV-GFP-P2A-mtTA and pAAV/TRE-HA-mGluR1, pHelper (Stratagene, USA), and pAAV2/9 (kindly provided by Dr. J. Wilson). The viral particles were purified using ammonium sulfate precipitation and iodixanol continuous gradient centrifugation as described previously [15]. The genomic titer of the purified AAV9 vector as determined by realtime PCR was $9.9 \cdot 10^{14}$ vector genomes $/ \mathrm{ml}$.

Ten microliters of adenoviral vector solution were 
injected into the subarachnoid space over the cerebellar vermis of 5-week-old (P35-38) anesthetized WT C57BL/6 mice. Most of the transduced cells were limited to PCs under control of the MSCV promoter.

Rotarod test. The motor behaviour of SCA1 transgenic mice was assessed by rotarod tests with an accelerating protocol (3 min acceleration from 4 to 40 revolutions per minute (rpm)) at days 1, 2, 3 and 4. The Rota-Rod Treadmill (MK-610; Muromachi Kikai, Japan) consisted of a gridded plastic rod $(3 \mathrm{~cm}$ in diameter, $10 \mathrm{~cm}$ long) flanked by two large round plates $(50 \mathrm{~cm}$ in diameter). The accelerating speed protocol contains 4 trials, with a 30 min interval between trials. We recorded the retention time that the mice spent on the rod. The cutoff time was set to $180 \mathrm{~s}$, and when the retention time (i.e., latency to fall) was over the cutoff time, the trial was interrupted and the cutoff time was recorded. The retention time was automatically measured, and time averaged across all the trials per day was used in the statistical analysis.

Biocytin infusion to PCs and immunohistochemistry. For visualisation of PC morphology, $0.5 \%$ biocytin (Sigma-Aldrich, USA) diluted in the intracellular solution was infused by passive diffusion through a patch pipette into whole cell-clamped PCs. Cerebellar slices were then fixed with $4 \%$ paraformaldehyde. After overnight fixation at $4^{\circ} \mathrm{C}$, the slices were rinsed in $0.1 \mathrm{M}$ PBS adjusted to $\mathrm{pH} 7.4$ ( 3 times, 5 min each), permeabilized and blocked with PBS containing 2\% $(\mathrm{v} / \mathrm{v})$ normal donkey serum, $0.1 \%(\mathrm{v} / \mathrm{v})$ Triton $\mathrm{X}-100$, and $0.05 \% \mathrm{NaN}_{3}$ (blocking solution). The slices were then rinsed in $0.1 \mathrm{M}$ PBS, pH 7.4 (3 times, $5 \mathrm{~min}$ each) and treated with streptavidin-conjugated Alexa $594(2 \mu \mathrm{g} / \mathrm{ml}$, Invitrogen, USA) for $2 \mathrm{~h}$ at room temperature. Visualized PC morphology was analyzed using a confocal laserscanning microscope (LSM 5 PASCAL, Carl Zeiss, Germany). The cerebellar slices were scanned at 1- $\mu \mathrm{m}$ intervals in Z-stack mode to project a whole dendritic tree onto a planar image, where the intensity of each pixel was scaled from 0 to 255 arbitrary units. Binary images of the biocytin-infused PCs were obtained by thresholding the projected images (i.e., areas brighter than 100 out of 255 arbitrary units were regarded as PC dendritic structures).

For immunohistochemistry, mice were perfused transcardially with a fixative containing $4 \%$ paraformaldehyde in $0.1 \mathrm{M}$ phosphate buffer after being anesthetized deeply. The whole brain was removed and postfixed in the same fixative for 5-6 h or overnight. The cerebellar vermis was cut into $50-\mu \mathrm{m}$ sagittal sections. The sections were treated with rabbit polyclonal anti-mGluR1 $\alpha$ (1:300; Frontier Institute, Japan) antibodies, and then visualized with Alexa Fluor 488-conjugated donkey anti-rabbit lgG (1:1,000; Life Technologies, USA). The antibodies were dissolved in a PBS solution containing $2 \%(\mathrm{v} / \mathrm{v})$ normal donkey serum, $0.1 \%(\mathrm{v} / \mathrm{v})$ Triton $\mathrm{X}-100$, and $0.05 \% \mathrm{NaN}_{3}$. Confocal fluorescence images of the cerebellar slices were obtained from the corresponding region of the cerebellum for comparison.
Statistical analysis. The results are expressed as the mean \pm SEM unless otherwise specified, and $n$ indicates the number of tested PCs. Statistical analyses of differences between the groups were performed using the unpaired t-test or one-way ANOVA followed by Tukey's post hoc test. Differences were considered significant if $\mathrm{p}<0.05$.

Results. SCA1 transgenic (B05) heterozygous mice which are selectively express expanded polyglutamine chain in PCs were used in this study [9]. According to the previous works [5], impairment of mGluR1 signaling in SCA model mice seems to be a hallmark of motor dyscoordination in the early stage of disease. To rescue SCA1 phenotype, we produced lentiviral and adenoviral vectors expressing mGluR1 and GFP proteins in a head of L7-4mCMV and MSCV promoters, respectively. Limitation of using AAV vectors is the insert capacity that should be ideally 4 kbit or less, while the capacity of lentiviral vectors is $8 \mathrm{kbit}$, almost twice as large as that of AAV vectors. For this reason we produced two adenoviral constructions (L7-4mCMV-GFP-P2A-mtTA and TRE-HA-mGluR1), which are dependently coexpress together and one lentiviral construction (MSCV-GFPP2A-mGluR1-WPRE). We made intracortical injection of adenoviral vectors into the mature cerebella (5-week-old mice) and lentiviral vectors to immature cerebellum of P6 SCA1 transgenic mice. According to our previous works connected with lentiviral expression of different gene constructs [5] the lentiviral injection to adult cerebellum caused the formation the small expression area limited of one-two lobes close to injection field. For this reason we used P6 SCA1 transgenic mice to increase the expression area. As a control substance we injected PBS to the SCA1 transgenic mice at the same age. We used also WT littermates as a control group. Mice were analyzed after 7 and 11 weeks respectively at P84-90 which is correlated with the early stage of disease in SCA1 patients.

Expression of mGluR by adenoviral and lentiviral vectors deteriorates motor performance in SCA1 transgenic mice. Adenovirally and lentivirally treated and PBS treated mice were tested on the accelerating rotarod apparatus. As suspected, PBS and adenovirally treated WT mice had no gait ataxia, but lentivirally treated mice showed decreasing the time of stay on a rotarod from day 3 during the experiment $(p<0.01$ at day 3 and 4 . Asterisks indicate statistically significant differences compared with PBS injected mice as determined by one-way ANOVA followed by Tukey's post hoc test) (Figure 1 (a)). In the group of SCA1 transgenic mice the negative pattern of lentiviral influence was more prominent and started also from day 3 during the experiment $(p<0.05$ at day 3 and $p<0.01$ at day 4 . Asterisks indicate statistically significant differences compared with PBS injected mice as determined by oneway ANOVA followed by Tukey's post hoc test) (Figure 1 (b)). These results indicate that expression of lentiviral vectors in cerebellum has the prominent negative influence on WT and SCA1 transgenic mice. 


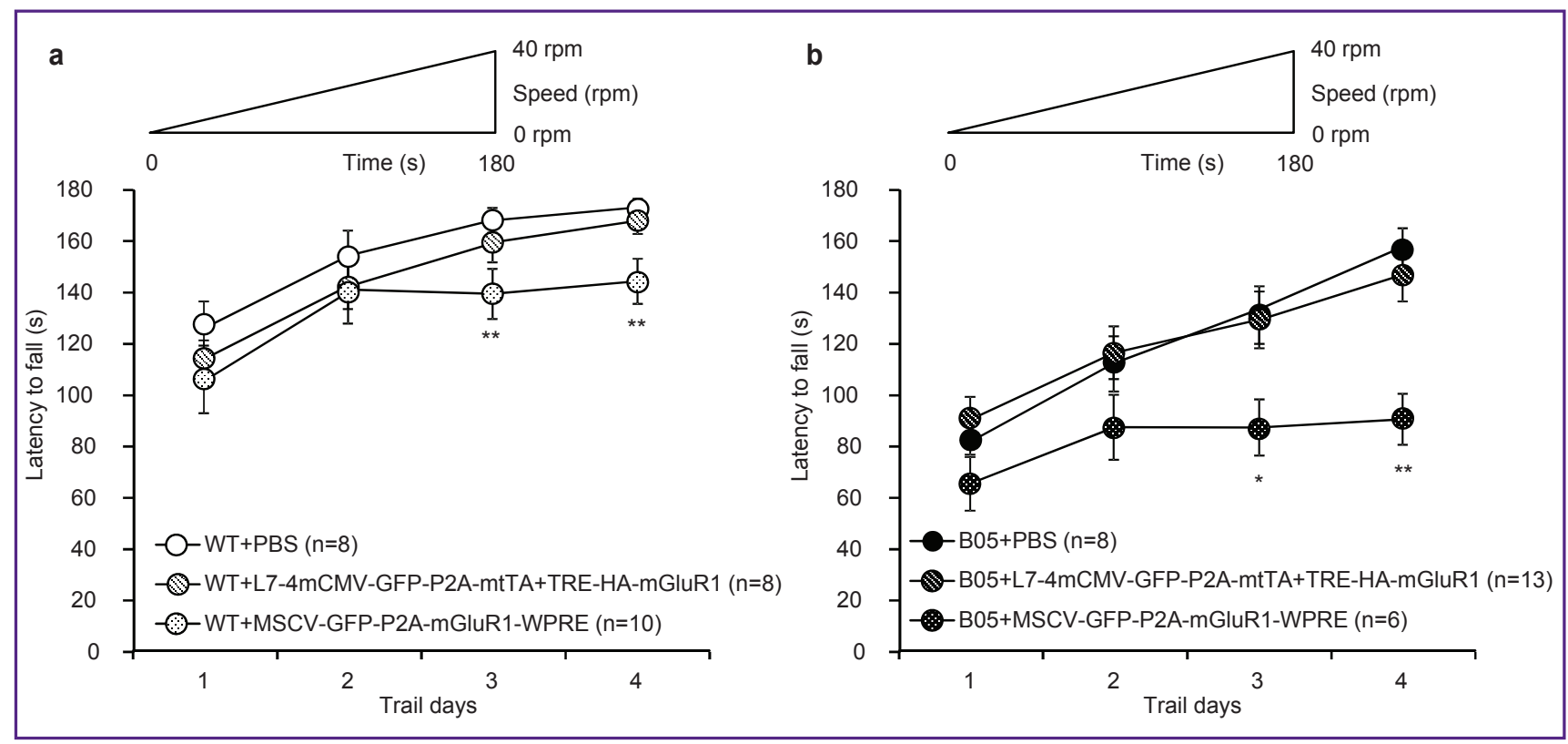

Figure 1. Rotarod performance of mice adenovirally and lentivirally treated with mGluR1 and GFP. As depicted in the graphs, the rod accelerated from 0 to $40 \mathrm{rpm}$ in $3 \mathrm{~min}$. All mice were examined at P84-90 (12 weeks). Seven weeks after the adenoviral and eleven weeks after lentiviral injection, mice were trained in four trials per day for 4 days. Naive littermates were used as controls in each group. (a) We observed impaired performance in WT mice treated with lentiviral vectors expressing mGluR1-GFP but not adenoviral vectors expressing mGluR1 and GFP. (b) The same pattern was seen in SCA1 transgenic mice adenovirally and lentivirally treated with mGluR1 and GFP. The number of mice tested is shown in parentheses. Asterisks indicate a statistically significant difference compared with noninjected mice, which was determined by one-way ANOVA followed by Tukey's post hoc test; * $p<0.05,{ }^{* *} p<0.01$

Selective expression of mGluR by adenoviral and lentiviral vectors alterates development of PCs in the cerebellum of WT and SCA1 transgenic mice in vivo. After the rotarod test, we examined the transduced area in the cerebellum and the localization of GFP and mGluR1 protein in PCs. Adenoviral infection gives very strong and generalized expression of mGluR1 and GFP almost all over the cerebellar lobes (Figure 2 (a)). While the lentiviral infection in adult mice can just affect two or three lobes closed to injection point (data is not shown). But injection to immature brain significantly increases strength and area of expression (Figure 2 (b)). In a comparison with PCs treated with PBS the PCs expressing the mGluR1 and GFP are smaller and have an impaired form of the dendritic tree (Figure 2 (a), (c)).

Electrophysiological analysis of PC sizes revealed significant differences in size of dendritic tree in PCs of WT PBS treated and WT adenoviral treated animals $(p<0.05$ in total size and $p<0.01$ in size of dendritic tree. Asterisks indicate statistically significant differences compared with PBS injected PCs as determined by an unpaired t test) (Figure 2 (d) and Table 1). In SCA1 transgenic group of mice the negative effect was more prominent. The total size of PCs treated with adenoviral and lentiviral vectors was significantly smaller than PBS treated one $(p<0.01$ and $p<0.05$, respectively. Asterisks indicate statistically significant differences compared with PBS injected PCs as determined by one-way ANOVA followed by Tukey's post hoc test) (Figure 2 (e) and Table 1). Size reduction of PCs was because of reduction of dendritic tree $(p<0.01$ and $p<0.05$, respectively. Asterisks indicate statistically significant differences compared with PBS injected PCs as determined by one-way ANOVA followed by Tukey's post hoc test) (See Figure 2 (e) and Table 1).

This finding shows the prominent negative effect of adenoviral and lentiviral expression of mGluR1 and GFP on PCs in vivo. This phenomenon could be explained not only by alteration of PCs maturation during brain development but also by involution processes in developed PCs.

Impairment of basic synaptic transmission in PFand CF-PC synapses in cerebellum adenovirally and lentivirally expressing exogenous mGluR1 protein. Then we examine the basic synaptic transmission in PF- and CF-PC in cerebellum adenovirally and lentivirally expressing mGluR1 and GFP. According to the strong correlation of dendritic tree size and general electrophysiological properties we suspected that small size of the PCs could lead to increasing the amplitude and rise and decay time of EPSCs in gene expressing PCs. We found that the most affected PCs are those adenovirally expressing mGluR1. SCA1 trangenic PCs expressing L7-4mCMV-GFP-P2A-mtTA and TRE-HA-mGluR1 has significantly bigger amplitude, and decreased rise and decay time of PF-EPSCs in comparison with PBS treated one $(p<0.05$. Asterisks 


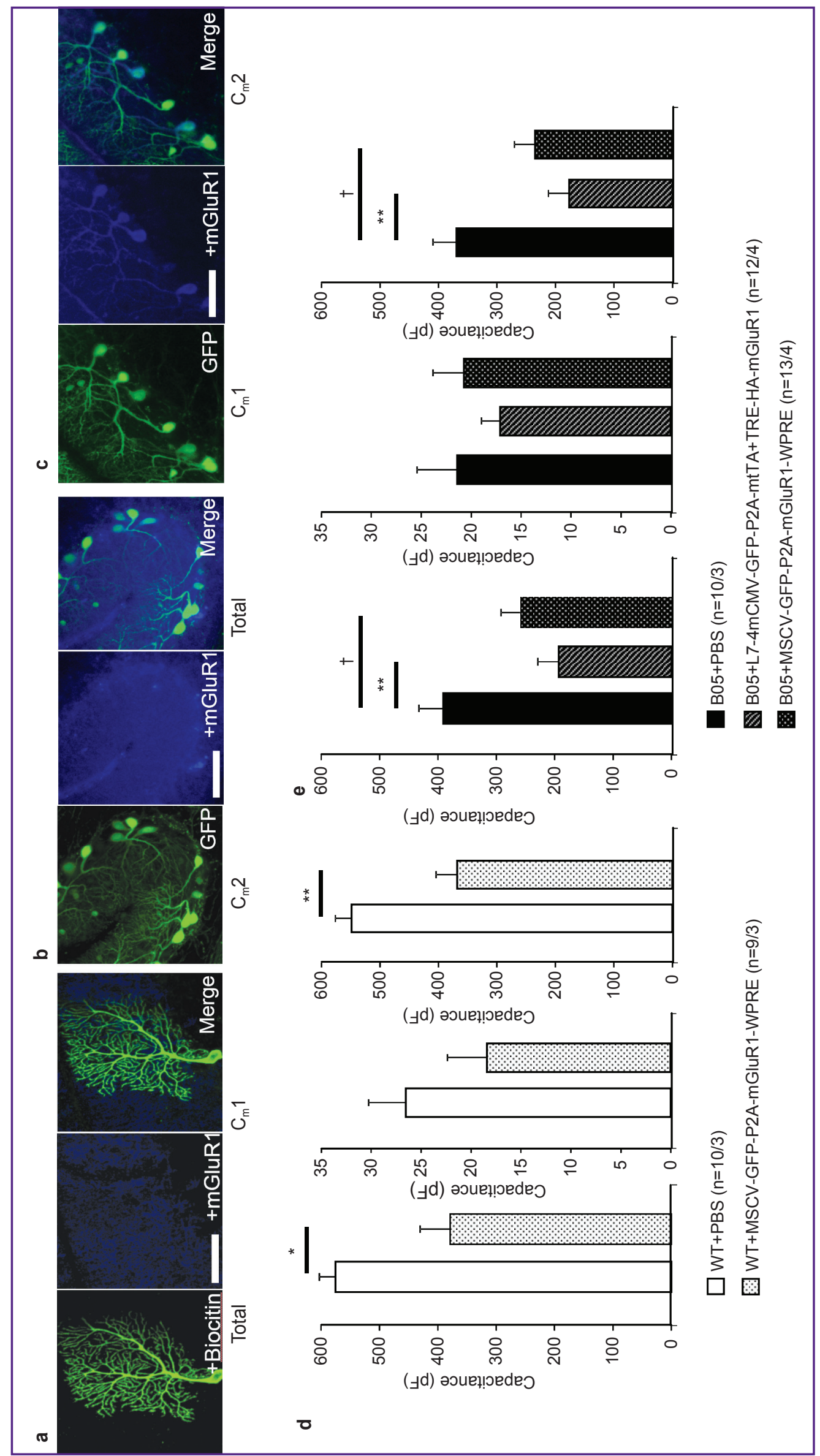

춯ㅎํ의

.

ब

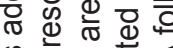

记 은. 온

政

बิ

들 ब

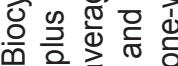

동

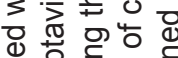

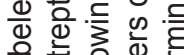

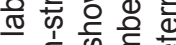

is क

人 잉

을 은

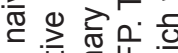

过范嵌

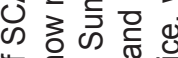

的 ब这

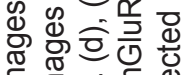

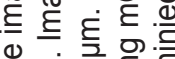

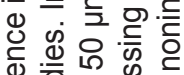

造

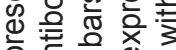

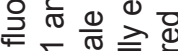

舟恕

엉 층

O) E $\stackrel{\Phi}{\Phi}$

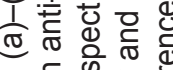

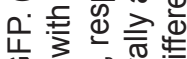

0

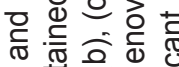

$\bar{x} \frac{\pi}{\pi}$

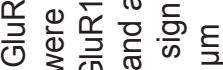

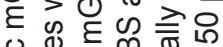

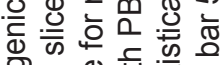

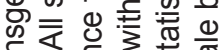

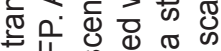

О门广

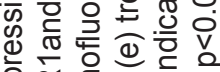

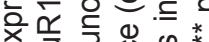

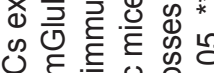

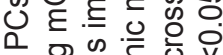

¿.

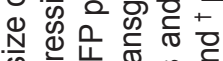

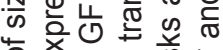

잉

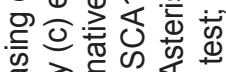

需

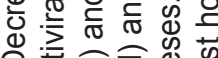

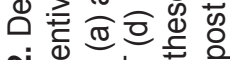

N

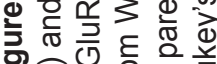

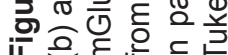


Table 1

Passive membrane properties of WT or SCA1 transgenic PCs adenovirally and lentivirally treated with exogenous mGluR1

\begin{tabular}{|c|c|c|c|c|c|}
\hline \multirow{2}{*}{ Mice and viral constructions } & \multicolumn{3}{|c|}{ Capacitance (pF) } & \multicolumn{2}{|c|}{ Resistance (M $\Omega)$} \\
\hline & Total & $C_{m 1}$ (soma) & $\mathrm{C}_{\mathrm{m}} 2$ (dendrites) & $\mathbf{R}_{\mathrm{a}}$ & $\mathrm{R}_{\mathrm{m}}$ \\
\hline WT+L7-4mCMV-GFP-P2A-mtTA+PBS $(n=10 / 3)$ & $575.1 \pm 27.6$ & $26.5 \pm 3.7$ & $548.5 \pm 27.8$ & $8.9 \pm 0.3$ & $246.3 \pm 20.4$ \\
\hline WT+MSCV-GFP-P2A-mGluR1-WPRE (n=12/3) & $379.0 \pm 51.4^{*}$ & $18.4 \pm 4.0$ & $360.6 \pm 37.1^{* *}$ & $8.0 \pm 0.4$ & $243.5 \pm 35.6$ \\
\hline B05+L7-4mCMV-GFP-P2A-mtTA+PBS (n=10/3) & $390.8 \pm 41.6$ & $21.4 \pm 4.0$ & $369.4 \pm 40.3$ & $8.4 \pm 0.4$ & $265.2 \pm 26.2$ \\
\hline B05+L7-4mCMV-GFP-P2A-mtTA+TRE-HA-mGluR1 ( $n=12 / 3)$ & $193.6 \pm 35.2^{\star *}$ & $17.1 \pm 1.9$ & $176.5 \pm 35.6^{* *}$ & $8.6 \pm 0.4$ & $275.0 \pm 37.6$ \\
\hline B05+MSCV-GFP-P2A-mGluR1-WPRE ( $n=10 / 3)$ & $259.3 \pm 32.6^{\dagger \dagger}$ & $20.7 \pm 3.1$ & $235.1 \pm 35.2^{\dagger}$ & $8.6 \pm 0.2$ & $243.0 \pm 13.9$ \\
\hline
\end{tabular}

$\mathrm{N}$ o te s. $\mathrm{C}_{\mathrm{m}} 1$ : membrane capacitance of soma; $\mathrm{C}_{\mathrm{m}} 2$ : membrane capacitance of dendrites; $\mathrm{R}_{\mathrm{m}}$ : membrane resistance; $\mathrm{R}_{\mathrm{a}}$ : access resistance. Values are expressed as the mean \pm standard deviation (SD). Asterisks indicate a statistically significant difference, as determined by an unpaired t test for WT animals and one-way ANOVA followed by Tukey's post hoc test for SCA1 transgenic animals, ${ }^{*}$ and ${ }^{\dagger} p<0.05,{ }^{* *}$ and ${ }^{\dagger \dagger} p<0.01$.

indicate statistically significant differences compared with PBS injected PCs as determined by one-way ANOVA followed by Tukey's post hoc test) (Figure 3 (b) and Table 2). WT and SCA1 trangenic PCs expressing MSCVGFP-P2A-mGluR1-WPRE was less affected (Figure 3 (a), (d)), but also we found decreasing the rise time in comparison with PBS treated PCs $(p<0.05$. Asterisks and cross indicate statistically significant differences compared with PBS injected PCs as determined by oneway ANOVA followed by Tukey's post hoc test) (See Table 2). It is interesting that adenoviral expression of mGluR1 is affected not by the paired pulse facilitation, but impaired paired pulse depression in PCs of SCA1 transgenic mice $(p<0.05$. Asterisks and cross indicate statistically significant differences compared with PBS injected PCs as determined by one-way ANOVA followed by Tukey's post hoc test) (Figure 3 (e) and Table 3 ).

This finding shows that overexpression of exogenous mGluR1 protein by lentiviral and especially adenoviral vectors disrupt basic synaptic transmission in PF and CF synapses in WT and SCA1 transgenic PCs.

Restoration of slow EPSC amplitude by adenoviral and lentiviral expression of transgenic mGluR1 protein. Activation of mGluR1 causes the opening of a nonselective transient receptor potential channels canonical type 3 (TRPC3) in PCs [8], which can be electrophysiologically recorded as a slow EPSC. Thus, this dependency TRPC3 channels from mGluR1 signaling can nicely show the real function of exogenous mGluR1 which was selectively express in PCs by adenoviral and lentiviral infection. According to our previous protocol we evoked slow EPSC by PF burst stimulation (10 or 25 pulses at $200 \mathrm{~Hz})$ in the presence of NBQX $(20 \mu \mathrm{M})$ to block AMPA receptor-mediated fast EPSCs [16].

In WT animals the endogenous mGluR1 expression seems to be saturated. For this reason, expression of MSCV-GFP-P2A-mGluR1-WPRE in WT PCs leads to nonsignificant enhancement of slow EPSC amplitude. The amplitudes of slow EPSCs evoked by 10 stimuli at $200 \mathrm{~Hz}$ were 251.2 $\pm 101.4 \mathrm{pA}$ ( $\mathrm{n}=10$ PCs from 3 PBS treated mice) and 264.7 \pm 69.2 pA ( $n=8$ PCs expressing MSCVGFP-P2A-mGluR1-WPRE from 3 animals) (Figure 4 (a)). Increasing the number of PF stimulations (25 stimuli at $200 \mathrm{~Hz}$ ) produced larger slow EPSCs in PBS treated PCs (350.5 \pm 110.4 pA, $n=10$ cells from 3 mice) and in PCs expressing MSCV-GFP-P2A-mGluR1-WPRE (495.6= $89.6 \mathrm{pA}, \mathrm{n}=8$ cells from 3 mice) (Figure 4 (c)). In both stimulation protocols, transgenic expression of mGluR1 did not significantly increase the amplitude of slow EPSCs ( $p>0.05$, as determined by an unpaired t test).

In contrast, the restoration of mGluR1 dependent slow EPSC was more prominent in PCs of SCA1 transgenic mice. The amplitudes of slow EPSCs evoked by 10 stimuli at $200 \mathrm{~Hz}$ were $39.9 \pm 8.6 \mathrm{pA}$ ( $\mathrm{n}=11 \mathrm{PCs}$ from 3 PBS treated mice), 153.2 $\pm 44.0 \mathrm{pA}$ ( $\mathrm{n}=15$ PCs expressing L7-4mCMV-GFP-P2A-mtTA and TRE-HAmGluR1 from 4 animals) and $133.8 \pm 55.5 \mathrm{pA}$ ( $\mathrm{n}=10 \mathrm{PCs}$ expressing MSCV-GFP-P2A-mGluR1-WPRE from 3 animals) $(p<0.05$. Asterisks indicate statistically significant differences between adenoviral and PBS treated PCs as determined by one-way ANOVA followed by Tukey's post hoc test) (Figure 4 (b)). Increasing the number of PF stimulations (25 stimuli at $200 \mathrm{~Hz}$ ) produced larger slow EPSCs in PBS treated PCs $(77.5 \pm 18.5 \mathrm{pA}, \mathrm{n}=11$ cells from 3 mice), PCs expressing L7-4mCMV-GFPP2A-mtTA and TRE-HA-mGluR1 (256.0 \pm 71.5 pA, n=15 cells from 4 animals) and in PCs expressing MSCV-GFPP2A-mGluR1-WPRE $(292.9=106.2$ pA, $n=10$ cells from 3 mice) $(p<0.05$. Asterisks and cross indicate statistically significant differences as determined by one-way ANOVA followed by Tukey's post hoc test) (Figure 4 (d)).

This data indicate that we succeeded to express transgenic mGluR1 and this transgenic mGluR1 is functional and takes part in metabolic processes in PCs.

Partial restoration of endocannabinoid dependent synaptic plasticity at cerebellar synapses by adenoviral and lentiviral expression of mGluR1 selectively in PCs. The synaptic activation of mGluR1 

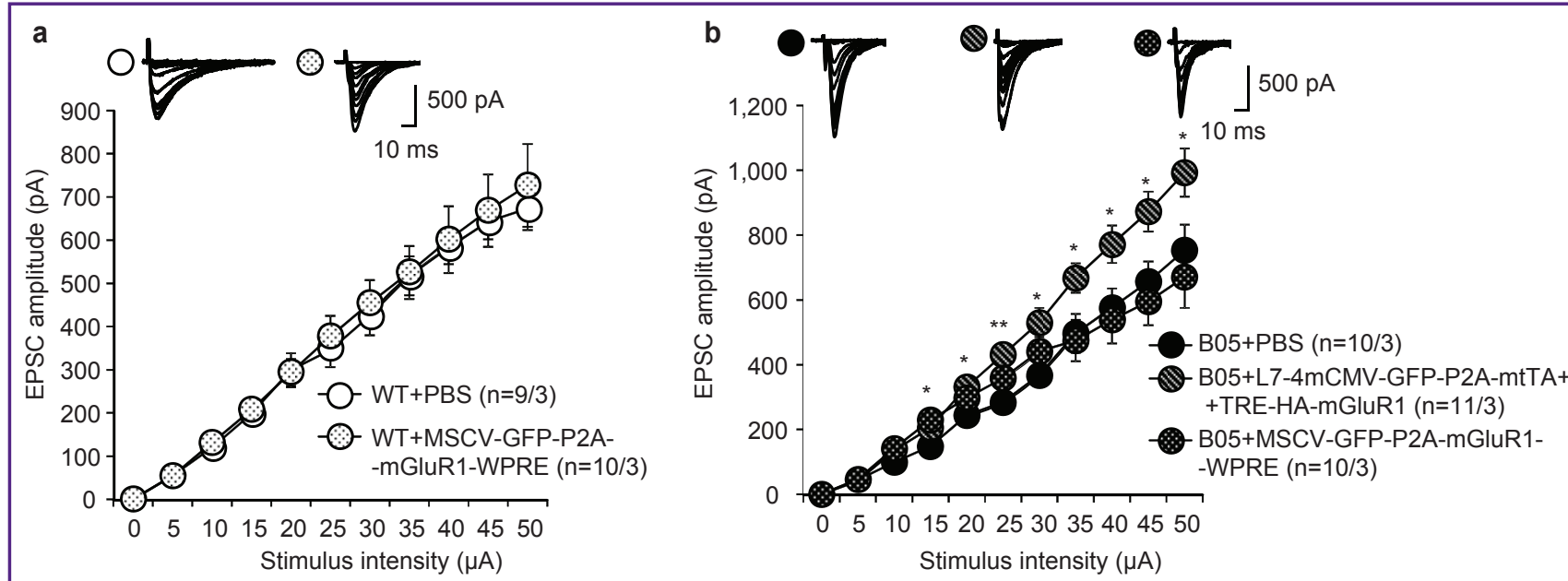

c

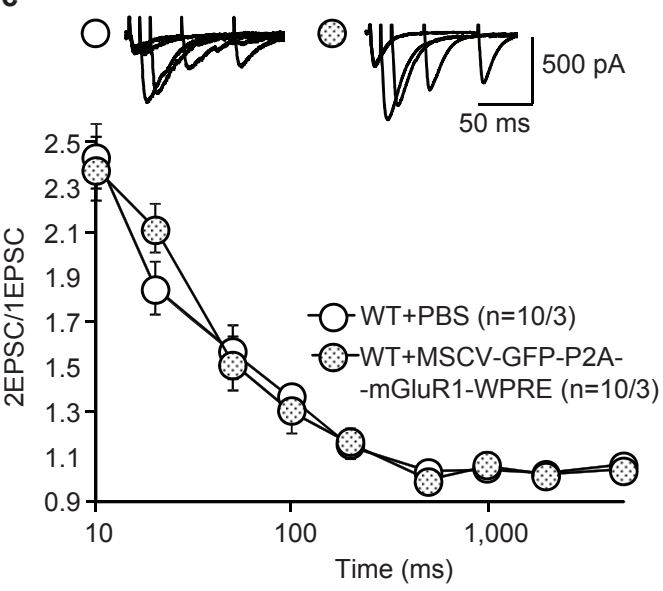

d
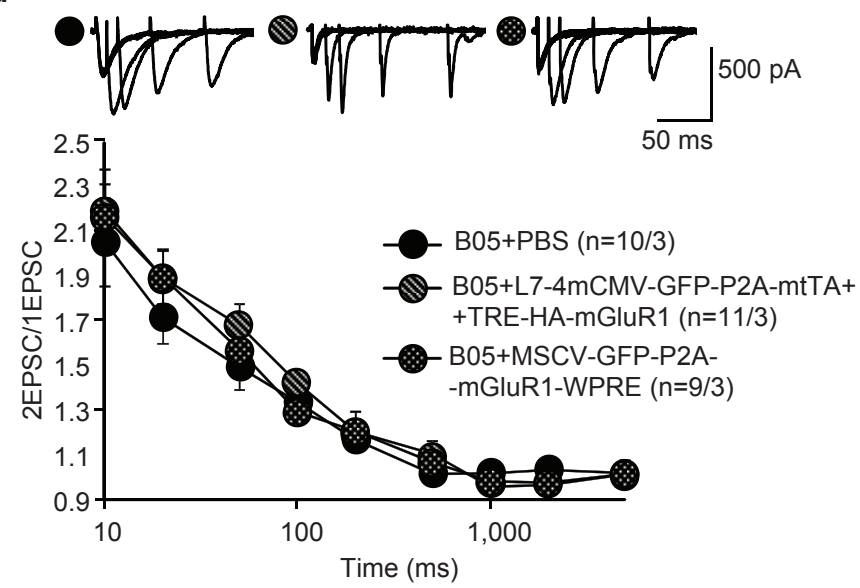

e
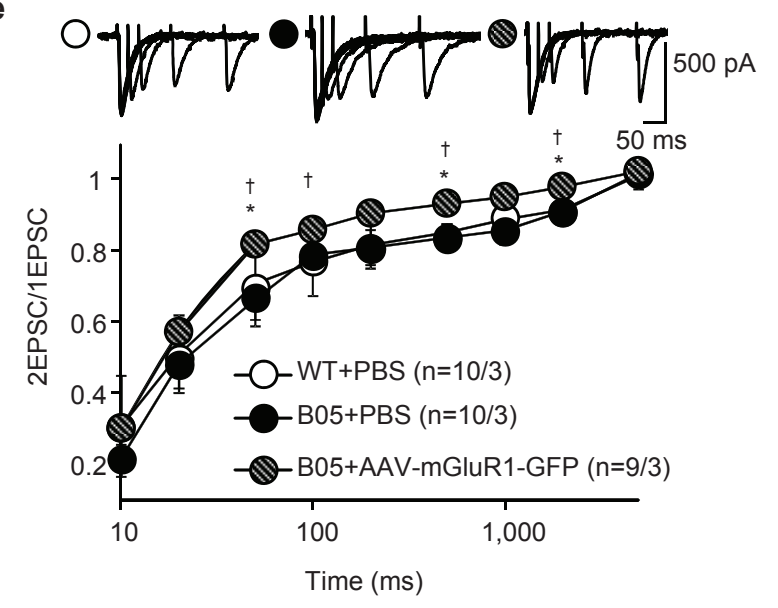

Figure 3. Lentivirally and adenovirally expressing exogenous mGluR1 worsening the basal excitatory synaptic transmission and short-term synaptic plasticity in PCs of SCA1 transgenic mice. (a), (b) Averaged input-output relationship of PF-mediated EPSCs in WT (a) and SCA1 transgenic mice (b) lentivirally and adenovirally treated with exogenous mGluR1. (c), (d) Paired pulse facilitation of PF-EPSCs recorded from PCs clamped at $-70 \mathrm{mV}$ from WT (c) and SCA1 transgenic mice (d). (e) Paired pulse depression of CF-mediated EPSCs recorded from PCs clamped at $-10 \mathrm{mV}$ from WT and SCA1 transgenic mice. Insets show representative PF-EPSC (a)-(d) and CF-EPSC (e) traces. The numbers ( $n$ ) of tested PCs and animals (PCs/animals) are indicated in each graph. The numbers of cells and animals tested is shown in parentheses. Asterisks and crosses indicate a statistically significant difference, which was determined by one-way ANOVA followed by Tukey's post hoc test; ${ }^{*}$ and ${ }^{\dagger} p<0.05,{ }^{* *} p<0.01$ 
Table 2

PF-EPSCs in WT or SCA1 transgenic PCs adenovirally and lentivirally treated with exogenous mGluR1

\begin{tabular}{lccccc}
\multicolumn{1}{c}{ Mice and viral constructions } & PF-EPSC $(\mathrm{pA})$ & PPF ratio & \multicolumn{2}{c}{ Rise time (ms) } & Decay \\
\hline WT+L7-4mCMV-GFP-P2A-mtTA+PBS $(n=10 / 3)$ & $770.9 \pm 96.1$ & $1.6 \pm 0.1$ & $2.8 \pm 0.3$ & $10.1 \pm 0.9$ \\
\hline WT+MSCV-GFP-P2A-mGluR1-WPRE $(n=12 / 3)$ & $877.0 \pm 209.8$ & $1.5 \pm 0.1$ & $1.9 \pm 0.3^{*}$ & $7.8 \pm 1.0$ \\
\hline B05+L7-4mCMV-GFP-P2A-mtTA+PBS $(n=10 / 3)$ & $752.9 \pm 82.9$ & $1.5 \pm 0.1$ & $2.3 \pm 0.2$ & $7.4 \pm 0.9$ \\
\hline B05+L7-4mCMV-GFP-P2A-mtTA+TRE-HA-mGluR1 $(n=12 / 3)$ & $908.0 \pm 83.8^{*}$ & $1.7 \pm 0.1$ & $1.7 \pm 0.1^{*}$ & $5.0 \pm 0.7^{*}$ \\
\hline B05+MSCV-GFP-P2A-mGluR1-WPRE $(n=10 / 3)$ & $724.2 \pm 98.8$ & $1.6 \pm 0.1$ & $1.5 \pm 0.3^{\dagger}$ & $5.6 \pm 0.6$ \\
\hline
\end{tabular}

$\mathrm{N}$ o t e s. Excitatory postsynaptic currents (EPSCs) were obtained by electrical stimulation of parallel fibers (PFs). Rise: rise time; decay: decay time constants; PPF: ratio of paired pulse facilitation. Values of PPF were obtained with an interpulse interval of $50 \mathrm{~ms}$. Values are expressed as the mean \pm standard deviation (SD). Asterisks indicate a statistically significant difference, as determined by an unpaired t test for WT animals and one-way ANOVA followed by Tukey's post hoc test for SCA1 transgenic animals, ${ }^{*}$ and ${ }^{\dagger} p<0.05$.

Table 3

CF-EPSCs in WT or SCA1 transgenic PCs adenovirally and lentivirally treated with exogenous mGluR1

\begin{tabular}{lccccc}
\multicolumn{1}{c}{ Mice and viral constructions } & CF-EPSC (pA) & PPD ratio & Rise time (ms) & Decay \\
\hline WT+L7-4mCMV-GFP-P2A-mtTA+PBS $(n=10 / 3)$ & $797.3 \pm 66.8$ & $0.7 \pm 0.0^{*}$ & $1.3 \pm 0.1$ & $8.1 \pm 0.8$ \\
\hline B05+L7-4mCMV-GFP-P2A-mtTA+PBS $(n=10 / 3)$ & $1,010.0 \pm 105.8$ & $0.7 \pm 0.1^{\dagger}$ & $0.9 \pm 0.0$ & $7.6 \pm 0.9$ \\
\hline B05+L7-4mCMV-GFP-P2A-mtTA+TRE-HA-mGluR1 $(n=12 / 3)$ & $1,029.0 \pm 128.2$ & $0.8 \pm 0.0$ & $0.9 \pm 0.2$ & $6.6 \pm 0.6$ \\
\hline
\end{tabular}

N o t e s. Excitatory postsynaptic currents (EPSCs) were obtained by electrical stimulation of climbing fibers (CFs). Rise: rise time; decay: decay time constants; PPD: ratio of paired pulse depression. Values of PPD were obtained with an interpulse interval of $50 \mathrm{~ms}$. Values are expressed as the mean \pm standard deviation (SD). Asterisks indicate a statistically significant difference, as determined by one-way ANOVA followed by Tukey's post hoc test for SCA1 transgenic animals, ${ }^{*}$ and ${ }^{\dagger} p<0.05$.

at PF-PC synapses induces the local release of endocannabinoid from PCs [7, 17]. The released endocannabinoid acts retrogradely on cannabinoid receptors on presynaptic PFs and then suppresses glutamate release from PF terminals for tens of seconds $[7,17]$. We examined this type of short-term plasticity, termed SSE, by monitoring AMPA receptor-mediated fast EPSCs at PF-PC synapses after PF burst stimulation to induce SSE [4]. In our previous study we show that the functional impairment of mGluRs and SSE disruption are prominent at 12 weeks of age in SCA1 transgenic mice [5]. The SSE measured in WT mice treated with PBS and MSCV-GFP-P2A-mGluR1-WPRE was similar (Figure 5 (a)), whereas in SCA1 transgenic mice it was reviled restoration of SSE in PCs adenovirally and lentivirally expressing mGluR1 protein. We reviled prominent suppression of PF-EPSC amplitudes in PCs expressing L7-4mCMV-GFP-P2A-mtTA and TRE-HAmGluR1 and MSCV-GFP-P2A-mGluR1-WPRE while in SCA1 transgenic PCs treated with PBS we saw slight facilitation of PF-EPSC (Figure 5 (b)). To exclude the possibility of multidependent endocannabinoid release during SSE, we examined the mGluR-independent form of endocannabinoid-mediated retrograde signaling, i.e., DSE. For DSE, endocannabinoid release from PCs is driven solely by an exceptionally large increase in intracellular calcium (in the range of a few micromolar), which is induced by depolarization and does not rely on activation of mGluRs [17-20]. In our case, DSE was observed in all groups of WT and SCA1 transgenic and we did not find any difference in strength and prolongation of DSE (Figure 5 (c) and (d)).

These findings indicate that adeno- and lentiviruses was express selectively in PCs and did not affect the presynaptic site. Overexpression of transgenic mGluR1 protein and the intact presynaptic site made normal release of endocannabinoids and partial restoration of SSE possible.

Impaired LTD expression in PCs expressing expanded ATXN1. Also, the LTD of fast EPSCs at PF-PC synapses requires postsynaptic mGluR1 signaling in PCs $[7,21]$. In our previous work we found impaired LTD in PCs of 12 week old SCA1 transgenic mice [5]. We therefore examined LTD in PCs adenovirally and lentivirally express transgenic mGluR1 protein. LTD was induced at PF-PC synapses in WT mice treated with PBS (values normalized to the basal response 30 min after induction: $69.4 \pm 6.1 \%, \mathrm{n}=5$ from 5 mice) to the same degree as in 


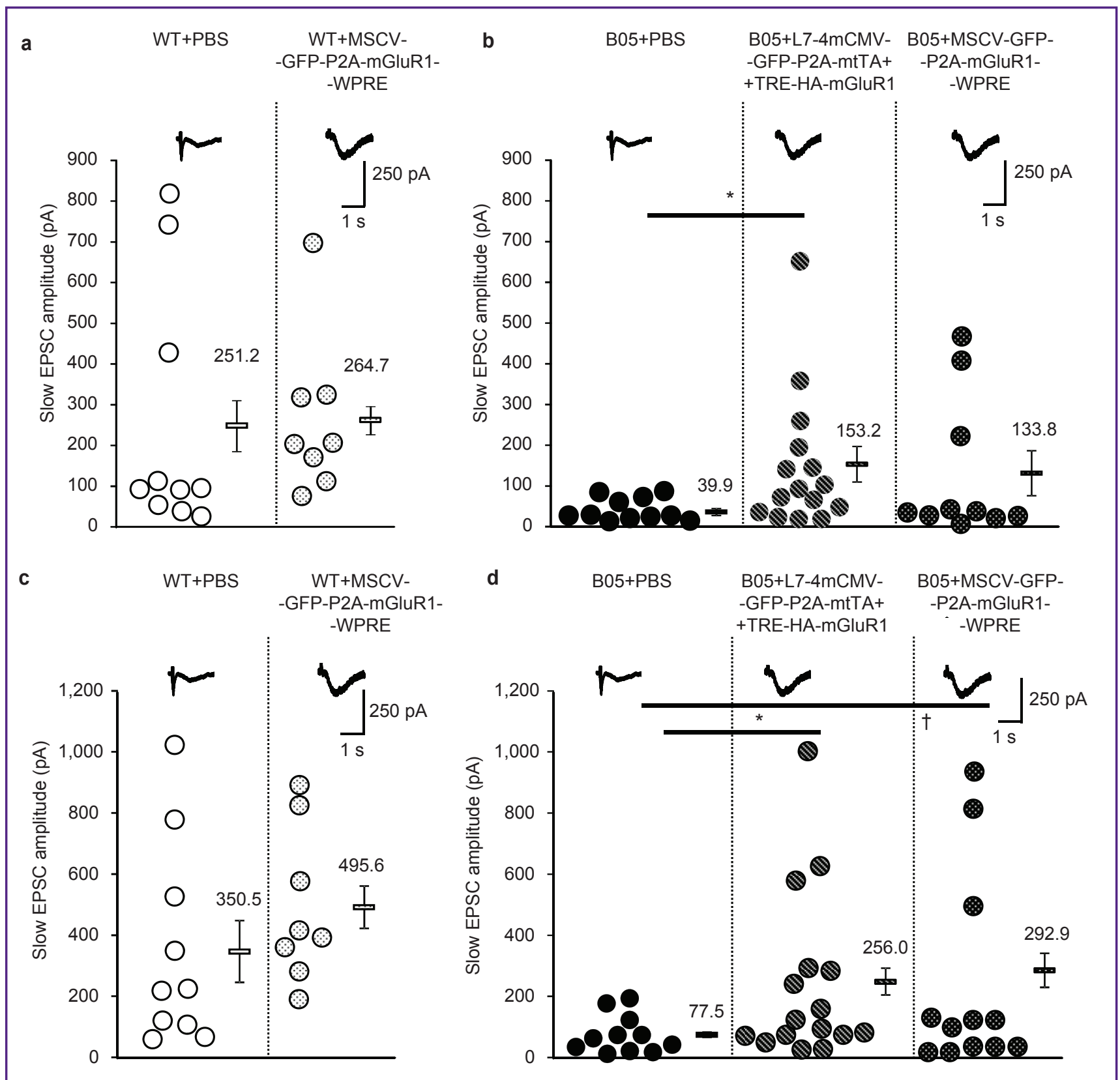

Figure 4. Restoration of mGluR1-mediated slow EPSCs in PCs of SCA1 transgenic mice adenovirally and lentivirally treated with exogenous mGluR1. EPSCs were evoked by electrical stimulation of PFs with 10 stimuli (a), (b) or 25 stimuli (c), (d) at $200 \mathrm{~Hz}$. Stimulus artefacts are partially truncated. The strength of electrical stimulation was adjusted before application of CNQX, an AMPA receptor antagonist, to obtain an amplitude of 500 pA for AMPA receptor-mediated EPSCs. The representative traces are shown in inserts on the top of each graph. (a), (b) Graphs showing the average amplitude and amplitudes from each cell of slow EPSCs from WT (a) and SCA1 transgenic (b) PCs upon electrical stimulation of PFs with 10 stimuli at $200 \mathrm{~Hz}$. (c), (d) Graphs showing the average amplitude and amplitudes from each cell of slow EPSCs from WT (c) and SCA1 transgenic (d) PCs upon electrical stimulation of PFs with 25 stimuli at $200 \mathrm{~Hz}$. Asterisks indicate statistically significant differences compared treated with untreated mice as determined by test for WT animals and one-way ANOVA followed by Tukey's post hoc test for SCA1 transgenic animals; * and ${ }^{\dagger} p<0.05$

WT mice treated with MSCV-GFP-P2A-mGluR1-WPRE (70.1 $\pm 2.1 \%, n=5$ from 5 mice) (Figure $6(\mathrm{a})$ ). In all groups of SCA1 transgenic mice basal response 30 min after LTD induction was abnormal without any statistical differences between them $(95.2 \pm 3.2 \%, n=5$ from 5 SCA 1 transgenic mice treated with PBS; 95.2 $\pm 3.8 \%, n=5$ from 5 SCA1 transgenic mice treated with L7-4mCMV-GFP-P2A-mtTA and TRE-HA-mGluR1 and $98.9 \pm 2.6 \%, n=5$ from 5 SCA1 transgenic mice treated with MSCV-GFP-P2A-mGluR1WPRE) (Figure 6 (b)). But during first 15 min after LTD 


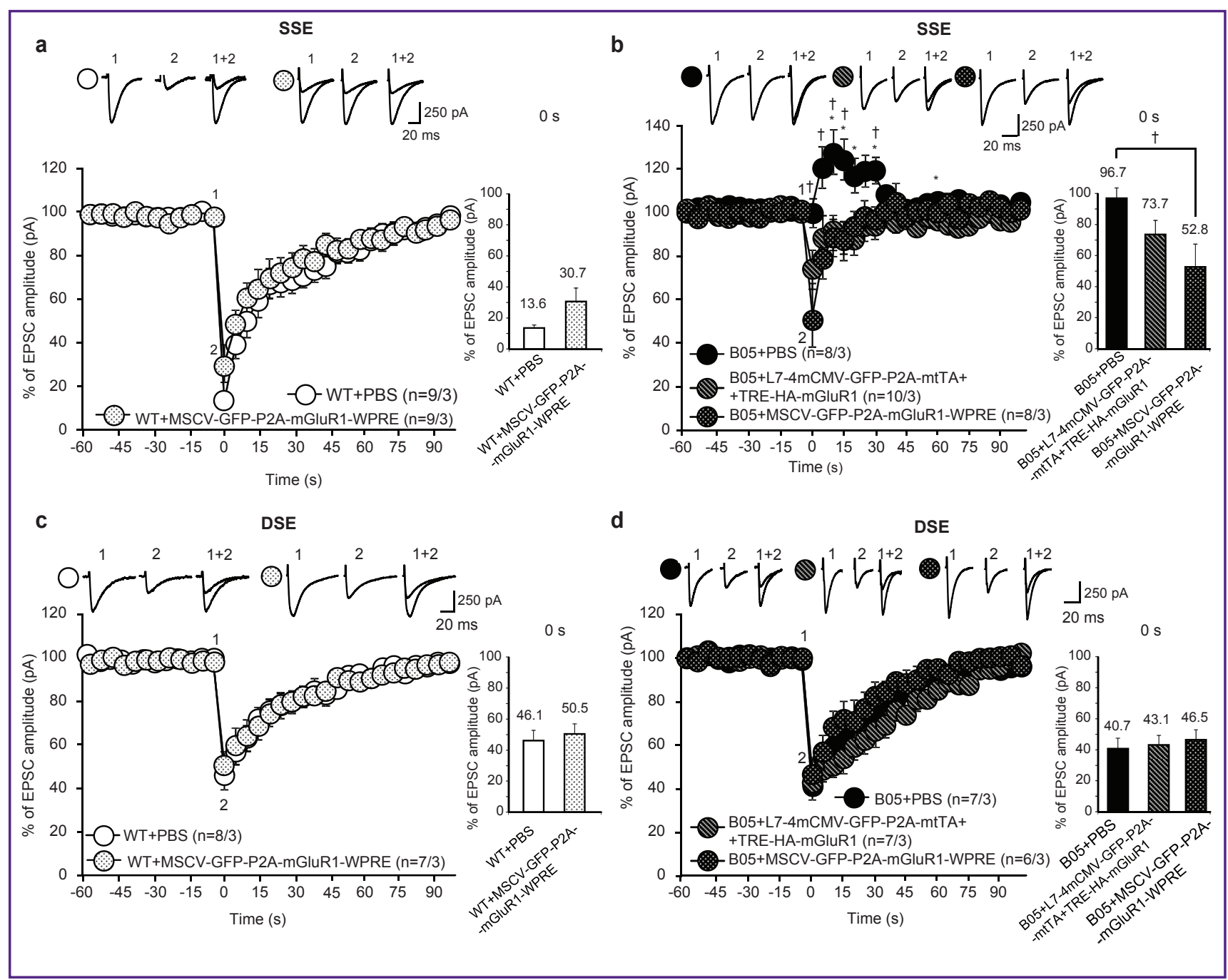

Figure 5. Restoration of SEE in adenovirally and lentivirally treated SCA1 transgenic mice with exogenous mGluR1. The amplitude of PF-EPSC was adjusted to approximately $400 \mathrm{pF}$ before induction of SSE or DSE. The SSE was induced by a PF burst ( 50 pulses at $100 \mathrm{~Hz}$ ), while DSE was evoked by depolarization of a PC from -70 to $0 \mathrm{mV}$ for $5 \mathrm{~s}$. (a), (b) Time course of changes in the PF-EPSC amplitude before and after the PF burst in WT (a) and SCA1 transgenic (b) PCs adenovirally and lentivirally treated with mGluR1. It was clearly showing the restoration of SSE in PCs of treated SCA1 transgenic animals. The right graph shows the percentage of the EPSC amplitude just after the PF burst relative to the baseline value (right). (c), (d) Time course of changes in the PF-EPSC amplitude before and after 5-second depolarization of WT (a) and SCA1 transgenic (b) PCs adenovirally and lentivirally treated with mGluR1. The right graph shows the percentage of the EPSC amplitude just after the depolarization. The inset traces in (a), (d) represent the last EPSC of the basal recordings (the EPSC just before the stimulation) (1) and the EPSC just after the PF burst (a), (b) and just after depolarization pulse (c), (d) in each experimental condition (2). The numbers ( $n$ ) of tested PCs and animals (PCs/animals) are indicated on the graph. Asterisks indicate a statistically significant difference, as determined by an unpaired t test for WT animals and one-way ANOVA followed by Tukey's post hoc test for SCA1 transgenic animals, * and ${ }^{\dagger} p<0.05$

induction the kinetics of PF-EPCS amplitudes of SCA1 transgenic PCs adenovirally and lentivirally expressing mGluR1 protein were different from PCs treated with PBS. We found very fast reversion of PF-EPSCs to the basal level at $4^{\text {th }}$ min in PCs treated with L7-4mCMV-GFP-P2AmtTA and TRE-HA-mGluR1 and at $5^{\text {th }}$ min in PCs treated with MSCV-GFP-P2A-mGluR1-WPRE. The PF-EPSCs at $5^{\text {th }}$ min after LTD induction were $87.6 \pm 5.3 \%(n=5$ from 5 SCA1 transgenic mice treated with PBS), 97.8 $\pm 2.0 \%(n=5$ from 5 SCA1 transgenic mice treated with L7-4mCMVGFP-P2A-mtTA and TRE-HA-mGluR1) and 102.9 $\pm 6.1 \%$ ( $n=5$ from 5 SCA1 transgenic mice treated with MSCVGFP-P2A-mGluR1-WPRE) ( $p<0.05$. Asterisks and cross indicate statistically significant differences as determined by one-way ANOVA followed by Tukey's post hoc test) (Figure 6 (b)). This result suggests that viral expression of mGluR1 failed to restore LTD in SCA1 transgenic mice in spite of overexpression of this protein in PCs. Moreover 


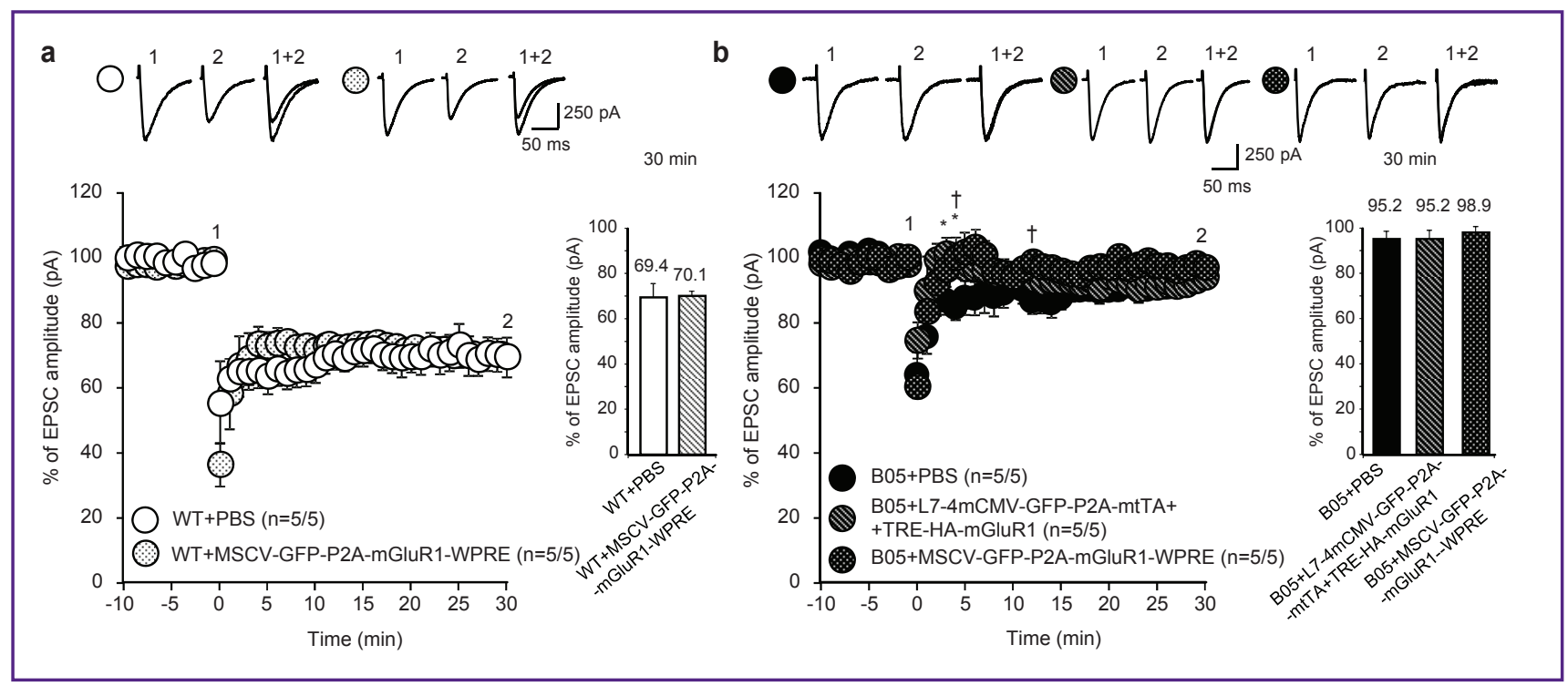

Figure 6. Adenovirally and lentivirally expressing exogenous mGluR1 worsening the long-term synaptic plasticity in PCs of SCA1 transgenic mice. Conjunctive stimulation of PF $(1 \mathrm{~Hz}, 30 \mathrm{~s})$ with depolarization was applied at time 0 . (a) Time course of changes in the PF-EPSC amplitude before and after conjunctive stimulation in WT untreated and lentivirally treated PCs with exogenous mGluR1. The right graph shows the percentage of the EPSC amplitude 30 min after the conjunctive stimulation relative to the baseline value. (b) Time course of changes in the PF-EPSC amplitude before and after conjunctive stimulation of SCA1 transgenic PCs adenovirally and lentivirally treated with exogenous mGluR1. The right graph shows the percentage of the EPSC amplitude $30 \mathrm{~min}$ after conjunctive stimulation relative to the baseline value. The inset traces in (a), (b) represent the last EPSC of the basal recordings (the EPSC just before the stimulation) (1) and the EPSC just after the conjunctive stimulation in each experimental condition (2). The numbers (n) of tested PCs and animals (PCs/animals) are indicated on the graph. Asterisks indicate a statistically significant difference, as determined by an unpaired test for WT animals and one-way ANOVA followed by Tukey's post hoc test for SCA1 transgenic animals, * and ${ }^{\dagger} p<0.05$

we found negative effect and aggravation of LTD during first 15 min after induction.

Discussion. In our previous work we found that SCA1 mice show prominent functional impairment of mGluRdependent signaling such as slow EPSCs, synaptic plasticity (SSE and LTD) and dendritic $\mathrm{Ca}^{2+}$ signals at $12^{\text {th }}$ postnatal week, prior to PC death. According to these findings we produced adenoviral and lentiviral vectors expressing mGluR1 to rescue ataxic phenotype in SCA1 transgenic mice. We suspected that transgenic mGluR1 protein can substitute the insufficient amount of endogenous one and restore the main types of synaptic plasticity in PCs which are highly involved in motor coordination. We succeeded to express mGluR1 and GFP selectively in PCs with a help of our constructions (See Figure 2 (a), (c) and Figure 4) but observed strong side effect. Unfortunately, instead of enhancement of mGluR1 signaling by activation of TRPC3 channels and SSE restoration, we found the time shortening of stay on the rotarod, distortion of PC morphology and failure of LTD rescue. Previously, different authors and our group showed that adenovirally and lentivirally GFP expression in a head of MSCV and L7 promoters is not changing the morphological and electrophysiological properties of PCs and behavioral phenotype of the transgenic animals [16, 22-24]. For this reason explanation of discovered phenomenon could be in the field of transcription of essential for PCs proteins, such as mGluR1, PcP2, calbindin, IP3 etc. Transcription of genes which are encoded these proteins is highly dependent on transcription factor RORa [2] (Figure 7). In physiological condition Ataxin 1 with the normal length of polyglutamine acts as a coactivator of transcription factor RORa. In SCA1 patients and model animals mutant Ataxin 1 fail the opportunity to connect with RORa and it leads to RORa degradation. In the case of transgenic expression of our lentiviral and adenoviral constructions in normal and pathological conditions, the amount of target genes is dramatically increasing, but the amount of RORa is not. For this reason we can suspect that abnormal occupation of RORa capacity by transgenic gene encoded mGluR1 leads to decreasing of other protein production such as IP3, calbindin, pcp2 etc. Pcp2 and calbindin are essential for PCs growth, differentiation and mice behavior [25, 26]. For this reason we can explain the decreasing of PC size and especially size of the dendritic tree in animals expressing transgenic mGluR1 (See Figure 2). Moreover, according to our rotarod results (See Figure 1 (b)), we suspected that expression of transgenic mGluR1 started in immature cerebellum will have a more prominent 


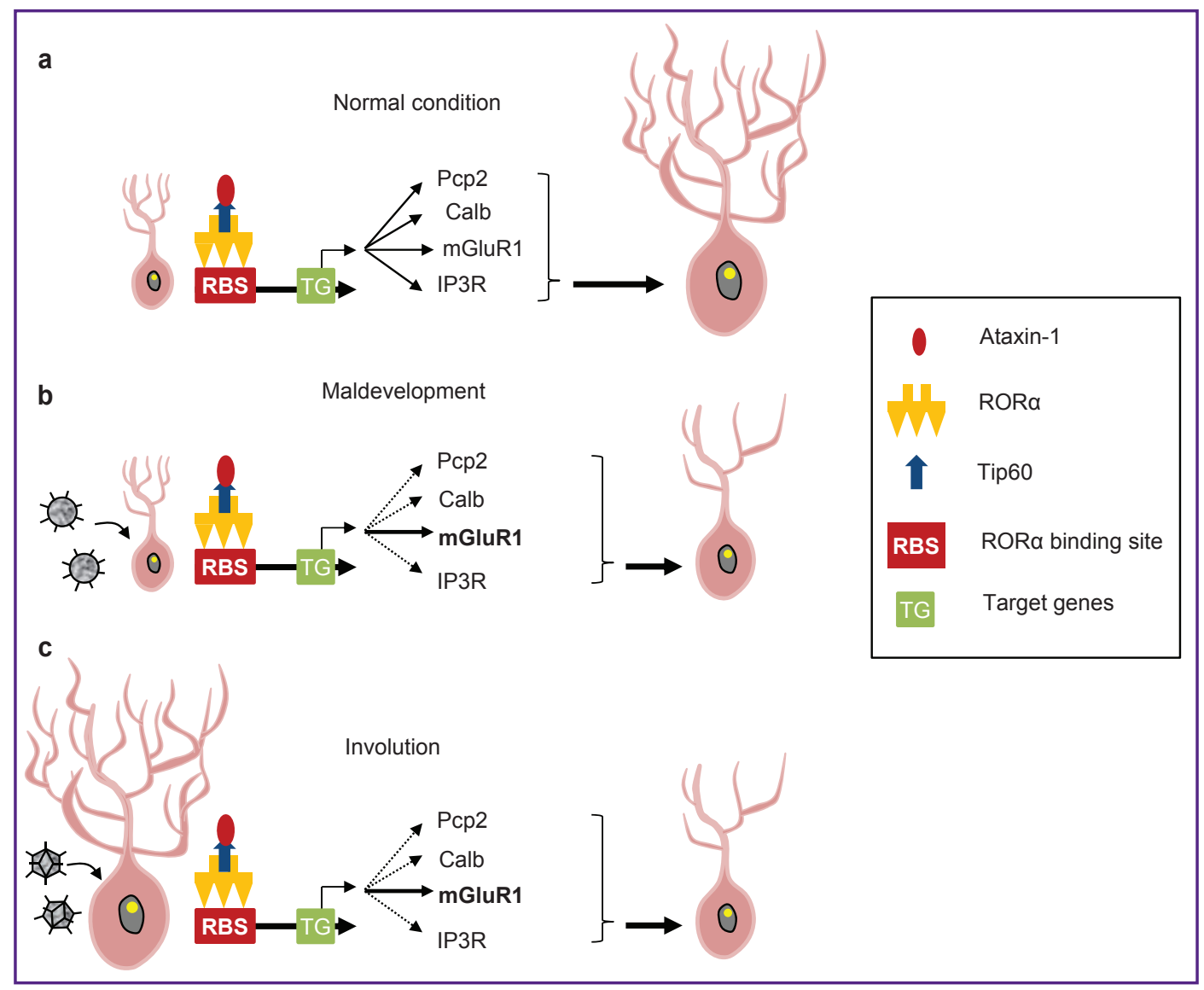

Figure 7. Potential mechanism of side effect of exogenous adenoviral and lentiviral mGluR1 treatment. Transcription complex which contains Ataxin 1, RORa and other proteins such as Tip 60, bandings with the specific site on the DNA strain (RORa binding site) and promote the transcription of certain genes. (a) In normal condition RORa is able to promote numerous specific genes. In presents of exogenous mGluR1 gene construct the constant amount of RORa starts to trigger the big amount of mGluR1 transcription and is not able to produce sufficient amount of proteins essential for cell growth and proliferation. In immature PCs (b) it prevents proper proliferation of PCs. In mature PCs (c) it leads to involution of PCs main structures, such as soma and dendrites

effect than in matured cerebellum. But we found that adenovirally treated PCs were smaller than lentivirally treated one (See Figure 2 (e)). Our findings show that side effect of transgenic expression of mGluR1 is connected not only with maldevelopment during ontogenesis but also with involution of adult PCs.

It is interesting that selective expression of transgenic mGluR1 in PCs did not affect the presynaptic site which leads to the normal release of endocannabinoids and restore of SSE in SCA1 transgenic mice (See Figure 5 (b)). But the failure of LTD restoration in SCA1 mice in the presence of transgenic mGluR1 could be explained by alteration of mGluR1 dependent pathway triggering the LTD. One player from this pathway is IP3 which is involved in $\mathrm{Ca}^{2+}$ release from the internal store and regulates the synaptic plasticity such as LTD [27]. Also it is interesting that in WT mice expressing transgenic mGluR1 the side effect is milder than in SCA1 mice in the same conditions (See Figure 1, Figure 3 (a), (b), (e) and Figure 6 (a), (b)). These data shows that in
SCA1 mice, partially degraded RORa, dramatically worsening the abnormal occupation effect of the transgenic mGluR1 gene in PCs. Totally our data shows that gene therapy by itself has its own complicity and ambiguousness of virus therapy benefit. Expression of transgene connected with numerous additional factors which should be studied before its introduction to the clinic and patient treatment.

Conclusion. Unfortunately we found the negative behavior effect of virus expression in mice cerebellum. Also it was shown that expression of these virus constructions leads to maldevelopment of PCs especially decrease of its dendritic arborization. From another side negative influence of mGluR1 overexpression did not spread to presynaptic site of PCs and we saw the rescue of short-term plasticity between PF and PC connected with endocannabinoid release in SCA1 transgenic mice. These virus constructs with overexpression of mGluR1 was not rescue the long term depression the essential form of synaptic plasticity. Enhancement of 
mGluR1 signaling by gene expression, led just to limited improvement of synaptic plasticity, but has prominent negative effect as alteration of motor performance, maldevelopment of PCs and worsening of long term depression in SCA1 transgenic mice. These results suggest that gene therapy by itself has its own complicity and ambiguousness of virus therapy benefit.

Acknowledgements. We thank Junko Sugiyama for maintaining and genotyping the SCA1 transgenic mice and Yasunori Matsuzaki for producing lentiviral and adenoviral vectors. The lentiviral vector and MSCV promoter were provided by St. Jude Children's Research Hospital and the American National Red Cross, respectively.

Author Contributions. ANS and $\mathrm{HH}$ designed the experiments. ANS performed the experiments. ANS wrote the paper with critical input from $\mathrm{HH}$ and $\mathrm{HH}$ supervised the project.

Conflicts of Interest. The authors declare no competing financial interests.

\section{References}

1. Orr H.T. SCA1-phosphorylation, a regulator of Ataxin-1 function and pathogenesis. Prog Neurobiol 2012; 99(3): 179185, https://doi.org/10.1016/j.pneurobio.2012.04.003.

2. Serra H.G., Duvick L., Zu T., Carlson K., Stevens S., Jorgensen N., Lysholm A., Burright E., Zoghbi H.Y., Clark H.B., Andresen J.M., Orr H.T. RORalpha-mediated Purkinje cell development determines disease severity in adult SCA1 mice. Cell 2006; 127(4): 697-708, https://doi.org/10.1016/j. cell.2006.09.036.

3. Sidman R.L., Lane P.W., Dickie M.M. Staggerer, a new mutation in the mouse affecting the cerebellum. Science 1962; 137(3530): 610-612, https://doi.org/10.1126/ science.137.3530.610.

4. Mitsumura K., Hosoi N., Furuya N., Hirai H. Disruption of metabotropic glutamate receptor signalling is a major defect at cerebellar parallel fibre-Purkinje cell synapses in staggerer mutant mice. J Physiol 2011; 589(Pt 13): 3191-3209, https:// doi.org/10.1113/jphysiol.2011.207563.

5. Konno A., Shuvaev A.N., Miyake N., Miyake K., lizuka A., Matsuura S., Huda F., Nakamura K., Yanagi S., Shimada T., Hirai H. Mutant ataxin-3 with an abnormally expanded polyglutamine chain disrupts dendritic development and metabotropic glutamate receptor signaling in mouse cerebellar Purkinje cells. Cerebellum 2014; 13(1): 29-41, https://doi.org/10.1007/s12311-013-0516-5.

6. Ferraguti F., Crepaldi L., Nicoletti F. Metabotropic glutamate 1 receptor: current concepts and perspectives. Pharmacol Rev 2008; 60(4): 536-581, https://doi.org/10.1124/ pr.108.000166.

7. Kano M., Hashimoto K., Tabata T. Type-1 metabotropic glutamate receptor in cerebellar Purkinje cells: a key molecule responsible for long-term depression, endocannabinoid signalling and synapse elimination. Philos Trans $R$ Soc Lond $B$ Biol Sci 2008; 363(1500): 2173-2186, https://doi.org/10.1098/ rstb.2008.2270.

8. Hartmann J., Dragicevic E., Adelsberger $H_{\text {., }}$ Henning A., Sumser M., Abramowitz J., Blum R., Dietrich A., Freichel M., Flockerzi V., Birnbaumer L., Konnerth A. TRPC3 channels are required for synaptic transmission and motor coordination. Neuron 2008; 59(3): 392-398, https://doi. org/10.1016/j.neuron.2008.06.009.

9. Burright E.N., Clark H.B., Servadio A., Matilla T., Feddersen R.M., Yunis W.S., Duvick L.A., Zoghbi H.Y., Orr H.T. SCA1 transgenic mice: a model for neurodegeneration caused by an expanded CAG trinucleotide repeat. Cell 1995; 82(6): 937-948, https://doi. org/10.1016/0092-8674(95)90273-2.

10. Torashima T., Okoyama S., Nishizaki T., Hirai H. In vivo transduction of murine cerebellar Purkinje cells by HIV-derived lentiviral vectors. Brain Res 2006; 1082(1): 11-22, https://doi. org/10.1016/j.brainres.2006.01.104.

11. Niwa H., Yamamura K., Miyazaki J. Efficient selection for high-expression transfectants with a novel eukaryotic vector. Gene 1991; 108(2): 193-199, https://doi.org/10.1016/03781119(91)90434-d.

12. Takayama K., Torashima T., Horiuchi H., Hirai H. Purkinje-cell-preferential transduction by lentiviral vectors with the murine stem cell virus promoter. Neurosci Lett 2008; 443(1): 7-11, https://doi.org/10.1016/j.neulet.2008.07.058.

13. Oue M., Mitsumura K., Torashima T., Koyama C., Yamaguchi H., Furuya N., Hirai H. Characterization of mutant mice that express polyglutamine in cerebellar Purkinje cells. Brain Res 2009; 1255: 9-17, https://doi.org/10.1016/j. brainres.2008.12.014.

14. Tamayose K., Hirai Y., Shimada T. A new strategy for large-scale preparation of high-titer recombinant adenoassociated virus vectors by using packaging cell lines and sulfonated cellulose column chromatography. Hum Gene Ther 1996; 7(4): 507-513, https://doi.org/10.1089/hum.1996.7. 4-507.

15. Miyake K., Miyake N., Yamazaki Y., Shimada T., Hirai Y. Serotype independent method of recombinant adenoassociated virus (AAV) vector production and purification. J Nippon Med Sch 2012; 79(6): 394-402, https://doi. org/10.1272/jnms.79.394.

16. Shuvaev A.N., Horiuchi H., Seki T., Goenawan H., Irie T., lizuka A., Sakai N., Hirai H. Mutant PKCY in spinocerebellar ataxia type 14 disrupts synapse elimination and long-term depression in Purkinje cells in vivo. $J$ Neurosci 2011; 31(40): 14324-14334, https://doi.org/10.1523/ JNEUROSCI.5530-10.2011.

17. Safo P.K., Cravatt B.F., Regehr W.G. Retrograde endocannabinoid signaling in the cerebellar cortex. Cerebellum 2006; 5(2): 134-145, https://doi.org/10.1080/ 14734220600791477.

18. Hashimotodani Y., Ohno-Shosaku T., Kano M. $\mathrm{Ca}(2+)$-assisted receptor-driven endocannabinoid release: mechanisms that associate presynaptic and postsynaptic activities. Curr Opin Neurobiol 2007; 17(3): 360-365, https:// doi.org/10.1016/j.conb.2007.03.012.

19. Kano M., Ohno-Shosaku T., Hashimotodani Y., Uchigashima M., Watanabe M. Endocannabinoid-mediated control of synaptic transmission. Physiol Rev 2009; 89(1): 309380, https://doi.org/10.1152/physrev.00019.2008.

20. Best A.R., Regehr W.G. Identification of the synthetic pathway producing the endocannabinoid that mediates the bulk of retrograde signaling in the brain. Neuron 2010; 65(3): 291-292, https://doi.org/10.1016/j.neuron.2010.01.030.

21. Gao Z., van Beugen B.J., De Zeeuw C.I. Distributed synergistic plasticity and cerebellar learning. Nat Rev Neurosci 2012; 13(9): 619-635, https://doi.org/10.1038/nrn3312. 
22. Irie T., Matsuzaki Y., Sekino Y., Hirai H. Kv3.3 channels harboring a mutation of spinocerebellar ataxia type 13 alter excitability and induce cell death in cultured cerebellar Purkinje cells. J Physiol 2014; 592(Pt 1): 229-247, https://doi. org/10.1113/jphysiol.2013.264309.

23. Huda F., Konno A., Matsuzaki Y., Goenawan H., Miyake K., Shimada T., Hirai H. Distinct transduction profiles in the CNS via three injection routes of AAV9 and the application to generation of a neurodegenerative mouse model. Molecular Therapy - Methods \& Clinical Development 2014; 1: 14032, https://doi.org/10.1038/mtm.2014.32.

24. Hirai H., Taisuke M., Wataru K., Shinji M., Masayoshi M., Watanabe M., Yuzaki M. Rescue of abnormal phenotypes of the $\delta 2$ glutamate receptor-null mice by mutant $\delta 2$ transgenes.
EMBO Reports 2005; 6(1): 90-95, https://doi.org/10.1038/ sj.embor.7400312.

25. Vassileva G., Smeyne R.J., Morgan J.I. Absence of neuroanatomical and behavioral deficits in L7/pcp-2-null mice. Mol Brain Res 1997; 46(1-2): 333-337, https://doi. org/10.1016/s0169-328x(97)00081-8.

26. Barski J.J., Hartmann J., Rose C.R., Hoebeek F., Mörl K., Noll-Hussong M., De Zeeuw C.I., Konnerth A., Meyer M. Calbindin in cerebellar Purkinje cells is a critical determinant of the precision of motor coordination. $J$ Neurosci 2003; 23(8): 3469-3477.

27. Finch E.A., Augustine G.J. Local calcium signalling by inositol-1,4,5-trisphosphate in Purkinje cell dendrites. Nature 1998; 396(6713): 753-756, https://doi.org/10.1038/25541. 